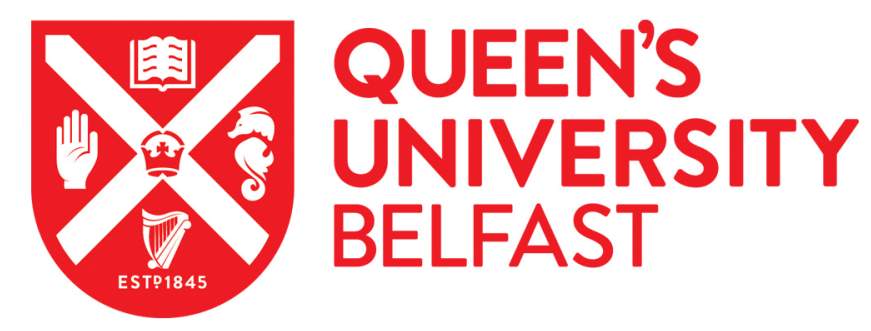

\title{
Experimental study on the ignition characteristics of cellulose, hemicellulose, lignin and their mixtures
}

Cao, W., Li, J., Martí-Rosselló, T., \& Zhang, X. (2018). Experimental study on the ignition characteristics of cellulose, hemicellulose, lignin and their mixtures. Journal of the Energy Institute.

https://doi.org/10.1016/j.joei.2018.10.004

Published in:

Journal of the Energy Institute

Document Version:

Peer reviewed version

Queen's University Belfast - Research Portal:

Link to publication record in Queen's University Belfast Research Portal

Publisher rights

(C) 2018 Elsevier Ltd.

This work is made available online in accordance with the publisher's policies. Please refer to any applicable terms of use of the publisher.

\section{General rights}

Copyright for the publications made accessible via the Queen's University Belfast Research Portal is retained by the author(s) and / or other copyright owners and it is a condition of accessing these publications that users recognise and abide by the legal requirements associated with these rights.

Take down policy

The Research Portal is Queen's institutional repository that provides access to Queen's research output. Every effort has been made to ensure that content in the Research Portal does not infringe any person's rights, or applicable UK laws. If you discover content in the Research Portal that you believe breaches copyright or violates any law, please contact openaccess@qub.ac.uk. 


\title{
Experimental Study on the Ignition Characteristics of Cellulose,
}

\section{Hemicellulose, Lignin and Their Mixtures}

\author{
Wenhan $\mathrm{Cao}^{\mathrm{a}}$, Jun $\mathrm{Li}^{\mathrm{a}^{*}}$, Teresa Martí-Rosselló ${ }^{\mathrm{a}}$, Xiaolei Zhang ${ }^{\mathrm{b}}$ \\ ${ }^{a}$ Department of Chemical and Process Engineering, University of Strathclyde, Glasgow, G1 IXJ, UK \\ ${ }^{b}$ School of Mechanical and Aerospace Engineering, Queen's University of Belfast, BT9 5AH, UK
}

\section{Abstract}

Ignition behaviour of biomass is an essential knowledge for plant design and process control of biomass combustion. Understanding of ignition characteristics of its main chemical components, i.e. cellulose, hemicellulose, lignin and their mixtures will allow the further investigation of ignition behaviour of a wider range of biomass feedstock. This paper experimentally investigates the influences of interactions among cellulose, hemicellulose and lignin on the ignition behaviour of biomass by thermogravimetric analysis. Thermal properties of an artificial biomass, consisting of a mixture of the three components will be studied and compared to that of natural biomass in atmospheres of air and nitrogen in terms of their ignition behaviour. The results showed that the identified ignition temperatures of cellulose, hemicellulose and lignin are $410^{\circ} \mathrm{C}, 370^{\circ} \mathrm{C}$ and $405^{\circ} \mathrm{C}$, respectively. It has been found that the influence of their interactions on the ignition behaviour of mixtures is insignificant, indicating that the ignition behaviour of various biomass feedstock could be predicted with high accuracy if the mass fractions of cellulose, hemicellulose and lignin are known. While the deficiencies of the determined mutual interactions would be further improved by the analytical results of the activation energies of cellulose, hemicellulose, lignin, their mixtures as well as natural and artificial biomass in air conditions.

Keywords: biomass; ignition temperature; kinetics; cellulose; hemicellulose; lignin

Corresponding author. Tel.: 01415482393

E-mail address: jun.li@strath.ac.uk 
Biomass is considered to be a carbon-neutral and renewable fuel, which holds a great potential to act as an alternative energy resource to address the challenging of global warming and worldwide energy crisis ${ }^{[1]}$. Compared with other thermal conversion technologies, direct combustion is known as the most efficient approach of biomass utilization for heat and power generation ${ }^{[2]}$. However, firing biomass in modified fuel boilers or co-firing biomass with coal in existing coal-fired boilers is a complicate process ${ }^{[3]}$, an optimal operation of the biomass combustion process requires essential knowledge of its combustion performances, especially

flame properties and ignition behaviour. Ignition plays a crucial role in combustion, having a significant impact on the boiler operation, energy efficiency, as well as in the gas emissions ${ }^{[4]}$. Ignition temperature and ignition delay time are known as two important operational indicators to initialise combustion processes ${ }^{[5]}$. Most ignition studies were conducted to control and minimise the self-ignition risks during transport, handling and processing biomass materials ${ }^{[6]}$, but ignition mechanism with regard to improvement of combustion performances are rarely reported.

Previous studies have attempted to investigate the ignition behaviour of biomass with the aim of improving and making the biomass co-firing performance comparable with that of coal. Riazza et al. ${ }^{[7]}$ reported that ignition behaviour of coal could be improved by adding biomass in an air or oxy-firing atmosphere, especially remarkable for high rank coals. Shan et al. ${ }^{[8]}$ investigated the ignition and combustion of single biomass pellets in a vertical heating tube furnace, and identified two possible ignition behaviours: homogeneous ignition of volatile and heterogeneous ignition on the biomass particles' surface. More recently, Li et al. ${ }^{[3]}$ conducted ignition tests of biomass particles by experimentally detecting the change of luminance inside of a down-fire reactor before and after biomass injection, and results revealed that there is a 
significant effect of particle size on the ignition temperature and ignition delay time, and suggested that the ignition mechanism of biomass could be switched between homogeneous ignition and heterogeneous ignition. However, biomass feedstock is a highly diverse solid fuel and its chemical composition varies greatly from one source to another, same as their ignition behaviour. Therefore, it is highly essential to develop fundamental knowledge that could potentially be used to predict ignition characteristics of a wider range of biomass feedstock.

Due to the major organic substances of biomass can be divided into three main chemical components: cellulose, hemicellulose and lignin ${ }^{[9]}$, their distinct thermal characteristics have been often applied as an effective means to provide generalised understandings of various thermal processes of biomass, as well as identify their mutual interactions along thermal conversion processes ${ }^{[10-13]}$. Thermal conversion of biomass has been studied on the basis of these three main components in recent, as well as their interactions, since the mutual interactions can affect their thermal behaviour. Raveendran et al. ${ }^{[10]}$ found no detectable interactions among the components during the thermal conversion process through the study of their thermal characteristics on the TGA and packed-bed pyrolyzer. Yang et al. ${ }^{[14]}$ also observed negligible interactions among the three components in their studies by using a TGA analyzer, as well as in Wang et al ${ }^{[13]}$ study. However, Worasuwannarak et al ${ }^{[11]}$ observed significant interactions between the components by studying the yield of liquid productions, similar interactions are also reported by Wang et al. ${ }^{[12]}$ and Stefanidis et al ${ }^{[15]}$. The ignition behaviour of biomass could also be affected by interactions among the major components during combustion process, such research however is rarely reported. Studying the performances of ignition behaviour of different component mixtures will allow a further identification of potential interactions among the major components, and also enables the prediction of the ignition behaviour of biomass feedstock.

Apart from the physical and chemical studies on the interactions, kinetic study on the 
interactions is rarely reported. Thermal conversion of biomass can be classified as heterogeneous chemical reaction, its reaction kinetics can be affected by its three key components ${ }^{[16,17]}$. Through the reaction kinetic study, the difference between activation energy $\left(E_{a}\right)$, and pre-exponential factor $(A)$ can be obtained to better understand the interactions among the components.

In this paper, first, we will characterise the ignition behaviour of the three main chemical components of biomass. Then, ignition characteristics of various mixtures of these chemical components will be fully discussed to quantify the effects of interactions between the organic components on the overall ignition behaviour. Finally, the ignition properties of mixtures of these chemical components to simulate an artificial biomass will be conducted and compared with that of natural biomass of wheat straw and soft wood, as well as the calculation of kinetic parameters, with the aim of identifying the potential interactions among them with regards to ignition behaviour.

\section{Materials and methods}

\subsection{Materials and sample preparation}

Cellulose and Xylan (corncob xylan) powder are purchased from Sigma-Aldrich, and lignin (dealkaline lignin) powder is purchased from Carbosynt. Xylan has been often considered as a representative molecule for hemicellulose ${ }^{[14]}$. The proximate and ultimate analysis of these samples as well as of the wheat straw and soft wood are presented in Table 1. As it can be observed from the analysis, the contents of volatile matter in cellulose and xylan is higher than in lignin, while lignin has a much higher fixed carbon and ash content. For lignocellulosic biomass, the largest component is cellulose with over $40 \%$ of its overall weight, which will be majorly converted to gaseous and liquid products during its thermal conversions; 
98 hemicellulose, the least stable component, accounts for approximately $30 \%$ by weight of initial

99 biomass; while lignin normally accounts for approximately $20 \%$ by weight, $40 \%$ of which

100 attributes to char yield after pyrolysis ${ }^{[18-20]}$.

101 Table 1. Proximate and ultimate data of biomass samples (wt. \%)

\begin{tabular}{cccccc}
\hline & Cellulose & Xylan & Lignin & Wheat Straw & Soft Wood \\
\hline Moisture $^{a r}$ & 2.70 & 2.90 & 3.20 & 2.30 & 3.50 \\
VM $^{d b}$ & 89.70 & 84.80 & 51.30 & 74.80 & 58.36 \\
Ash $^{d b}$ & 1.70 & 1.70 & 15.00 & 7.40 & 1.12 \\
$\mathrm{FC}^{d b}$ & 8.60 & 13.50 & 33.70 & 17.80 & 40.52 \\
$\mathrm{C}^{d b}$ & 42.18 & 38.41 & 62.09 & 45.20 & 58.28 \\
$\mathrm{H}^{d b}$ & 6.15 & 6.18 & 5.88 & 5.25 & 4.71 \\
$\mathrm{O}^{d b}$ & 51.66 & 55.40 & 30.52 & 48.84 & 36.51 \\
$\mathrm{~N}^{d b}$ & 0.01 & 0.01 & 0.51 & 0.71 & 0.50 \\
\hline
\end{tabular}

db: dry basis; ar: as received

\subsection{Experiment design}

Table 2. Summary of testing conditions

\begin{tabular}{|c|c|c|c|c|}
\hline & & $\begin{array}{l}\text { Mixing ratio } \\
(\%)\end{array}$ & $\begin{array}{l}\text { Heating rate } \\
\left({ }^{\circ} \mathrm{C} / \mathrm{min}\right)\end{array}$ & $\begin{array}{l}\text { Final temp. } \\
\left({ }^{\circ} \mathrm{C}\right)\end{array}$ \\
\hline \multirow{5}{*}{ Individual samples } & Cellulose & - & 20 & 900 \\
\hline & Xylan & - & 20 & 900 \\
\hline & Lignin & - & 20 & 900 \\
\hline & Wheat straw & - & 20 & 900 \\
\hline & Soft wood & - & 20 & 900 \\
\hline \multirow{3}{*}{$\begin{array}{l}\text { Mixture } \\
\text { samples }\end{array}$} & Cellulose / Xylan & $50 / 50$ & 20 & 900 \\
\hline & Cellulose / Lignin & $50 / 50$ & 20 & 900 \\
\hline & Xylan / Lignin & $50 / 50$ & 20 & 900 \\
\hline \multirow[t]{2}{*}{ Artificial samples* } & Wheat straw & $\begin{array}{c}\text { Cellulose / Xylan / Lignin } \\
61.3 / 19.3 / 19.4\end{array}$ & 20 & 900 \\
\hline & Soft wood & $\begin{array}{c}\text { Cellulose / Xylan / Lignin } \\
43.1 / 24.1 / 32.8\end{array}$ & 20 & 900 \\
\hline
\end{tabular}

* The ratio is summarised from the literature [13, 21]

106 The Coning and Quartering Method ${ }^{[22]}$ is applied to prepare the mixture samples in this study.

107 This method has demonstrated its advantages for preparation of samples with poor flowability,

108 which can reduce the sampling size of the powder sample without generating a systematic bias.

109 Individual samples are mixed in a container according to the predetermined mixing ratio in the

110 experiment design, as detailed in Table 2, followed by the mixing procedures: 1) pour a cone 
of the mixture into a plate; 2) divide the cone into halves; 3 ) divide the cone into quarters; 4) discard the two opposite quarters of the sample; 5) recombine the remaining sample. The procedure is repeated three times to prepare each mixture sample. A total of 10 samples are prepared, as listed in Table 2.

\subsection{Estimation of the ignition temperature}

116 Ignition temperature is identified as the lowest temperature at which a solid fuel starts to ignite 117 without the aid of an external ignition sources. In theory, ignition temperature is the temperature to which a fuel-air mixture must be increased so that the heat evolved by the exothermic reactions of the combustion system will just overbalance the rate at which heat is discharged to the surroundings ${ }^{[23]}$. Ignition temperature of solid fuels is often determined by empirical methods through thermogravimetric (TG) and differential thermogravimetric (DTG) curves, such as: (1) identify the temperature at which the mass loss curve in the combustion

\subsection{Determination of kinetics}


134 The kinetics of biomass thermal conversions can be expressed by following equation:

$$
\frac{d \alpha}{d t}=k(T) f(\alpha)=A \exp \left(\frac{-E_{a}}{R T}\right) f(\alpha)
$$

where $T$ is the absolute temperature; $R$ is the gas constant; $f(\alpha)$ is the mass conversion function; $\alpha$ is the conversion fraction, which represents the relationship between the initial mass $\left(m_{0}\right)$ and the final mass $\left(m_{\infty}\right)$, and the current mass $(m)$ of the sample, as given below:

$$
\alpha=\frac{m_{0}-m}{m_{0}-m_{\infty}}
$$

When the heating rate $(\beta=d T / d t)$ is constant, Eq. 1 can be integrated as:

$$
g(\alpha)=\int_{0}^{\alpha} \frac{d \alpha}{f(\alpha)}=\frac{A}{\beta} \int_{0}^{T} d T \exp \left(-\frac{E_{a}}{R T}\right)
$$

where $g(\alpha)$ is an integrate function, consequently, Eq.3 can be approximated by:

$$
\ln \left[\frac{g(\alpha)}{T^{2}}\right]=\ln \left[\frac{A R}{\beta E_{a}}\left(1-\frac{2 R T}{E_{a}}\right)\right]-\frac{E_{a}}{R T}
$$

The conversion function $f(\alpha)$ depends on the operating conditions and the stage of the combustion. Combustion is a complicated process, which normally can divided into three different reaction stages ${ }^{[29]}$, or two parallel reactions with three reaction stages ${ }^{[30]}$, or more recently two-stage reactions with the first step that occurs at lower temperature and the second step that occurs the oxidation of char at higher temperature ${ }^{[31]}$. Thermal decomposition of biomass has been commonly described as first-order reaction ${ }^{[32]}$. In this study, we consider the combustion process with two-stage reaction mechanism, and both stages are governed by the first order reaction law. In this case, $f(\alpha)=(1-\alpha)$, as a result, $g(\alpha)=-\ln (1-\alpha)$, and for most system $R T / E_{a} \ll 1^{[33]}$, then Eq.4 can be approximated by:

$$
\ln \left[\frac{-\ln (1-\alpha)}{T^{2}}\right] \approx \ln \left(\frac{A R}{\beta E_{a}}\right)-\frac{E_{a}}{R T}
$$

The left hand side of Eq.5 is plotted against 1/T for the data from a single heating rate, which leads to a straight line, from which the activation energy can be obtained as the slope of this line, and the pre-exponential factor is derived from its intercept. 
Fig. 1 (a-c) show the mass loss profiles of cellulose, xylan and lignin in air and nitrogen atmospheres at a heating rate of $20^{\circ} \mathrm{C} / \mathrm{min}$ up to a final temperature of $900^{\circ} \mathrm{C}$. Due to the different chemical structures of the individual components, substantial differences in the thermal characteristics among them could be expected ${ }^{[34]}$.

Fig. 1 (a) shows that cellulose starts to decompose at a temperature of $325^{\circ} \mathrm{C}$ and losses over $80 \%$ of its mass before $410^{\circ} \mathrm{C}$, which is close to the content of its volatile matter as shown in Table 1 . When temperature is greater than $410^{\circ} \mathrm{C}$, the mass loss curves along its pyrolysis and combustion processes start to diverge, where the pyrolysis curve tends to flatten without further decomposition, and the solid residues account for approximately $8 \%$ of its initial mass at the end of the process; while the combustion curve shows that a continuous mass loss occurred until $600^{\circ} \mathrm{C}$ with less than $1 \%$ inert residues left in the end. The difference between the amounts of solid residue after pyrolysis and combustion processes equals to the content of the fixed carbon in cellulose. Fig.1 (b) shows that the decomposition of xylan starts at the temperature of $190^{\circ} \mathrm{C}$ and the divergence of its pyrolysis and combustion curves occurs at $370^{\circ} \mathrm{C}$, where the pyrolysis rate is getting stable while a second drop of mass occurs in combustion process due to char oxidation. The solid residue left after pyrolysis and combustion processes are $18 \%$ and $1.5 \%$ of the initial mass of xylan respectively.

In Fig.1 (c), the show shows that the decomposition of lignin starts at $210^{\circ} \mathrm{C}$ and the curves of pyrolysis and combustion diverged at $405^{\circ} \mathrm{C}$. A slow decomposition of lignin is noticed at the temperature ranges from $405^{\circ} \mathrm{C}$ to $750^{\circ} \mathrm{C}$ in its pyrolysis, and the remaining accounts for approximately $45 \%$ of its initial mass after pyrolysis; while in combustion, lignin loses more than half of its mass at the temperature ranges from $405^{\circ} \mathrm{C}$ to $600^{\circ} \mathrm{C}$, and there is $15 \%$ of its 


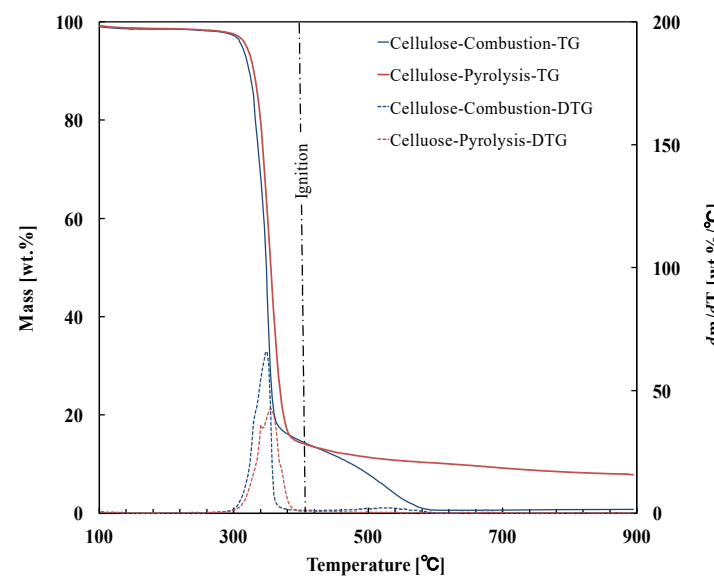

(a) Cellulose

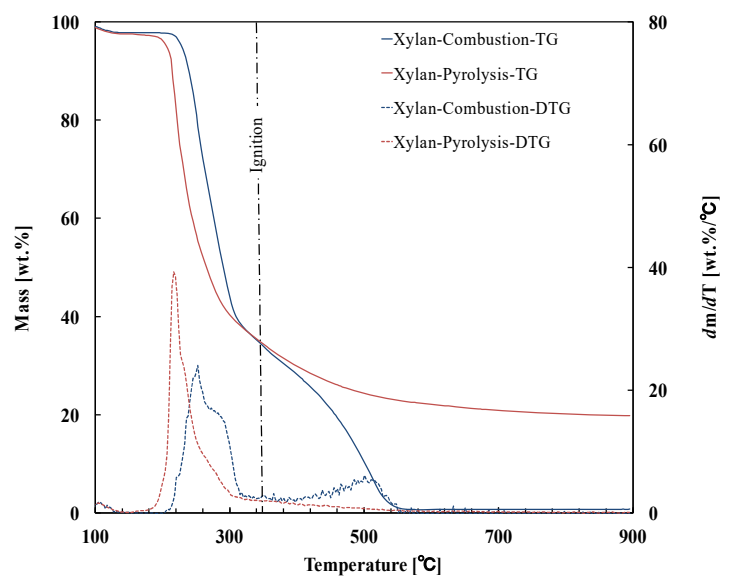

(b) Xylan

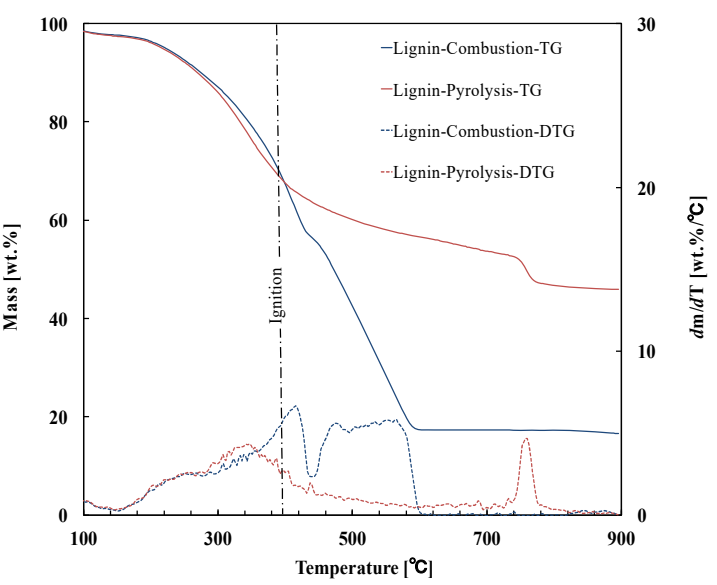

(c) Lignin

Fig.1. Thermal characteristics of individual chemical components in air (combustion) and nitrogen (pyrolysis) with identified ignition temperatures

By comparing TGA profiles of cellulose, xylan, and lignin in Fig.1, nearly all of their mass loss curves of pyrolysis and combustion processes coincide on top of the each other before the divergence occurred, a slight deviation might be caused by the difference of thermal conductivity of nitrogen and air ${ }^{[3]}$. This implies that, at the early stage of thermal conversion, temperature is the dominant factor of the reactions, rather than the existence of oxygen. Among these three samples, cellulose has the narrowest decomposition temperature range 
and lost the most of its mass during the decomposition process, while lignin has the widest decomposition temperature range and generates the most residual. The ignition temperatures of cellulose, xylan, and lignin are $410^{\circ} \mathrm{C}, 370^{\circ} \mathrm{C}$, and $405^{\circ} \mathrm{C}$ respectively. These temperatures are identified as the diverging point of TG curves and are the same temperatures at which the second peak appears in the DTG curves under air conditions.

\subsection{Ignition characteristics of mixtures of xylan, cellulose, and lignin}

The thermal behaviour (mass loss) of the mixtures could be predicted using the weighted sum of the partial contributions of individual components ${ }^{[10]}$ as described by the following equation:

$$
\frac{d m_{m i x}}{d t}=\sum_{i} y_{i} \frac{d m_{i}}{d t}
$$

where $y_{i}$ refers to the mass fraction of component $i$ in the mixture. So that the TG and DTG curves could be drawn based on the calculation results, and then the ignition temperatures of these mixtures would be predictable. To quantify the interactions of individual components on the ignition temperature of mixtures, the thermal tests of various mixtures of chemical components in air and nitrogen are performed and the results along with the predicted thermal characteristics of the mixtures are shown in Fig.2 (a-c). The potential impacts of interactions on the determined ignition temperatures will be discussed in this section.

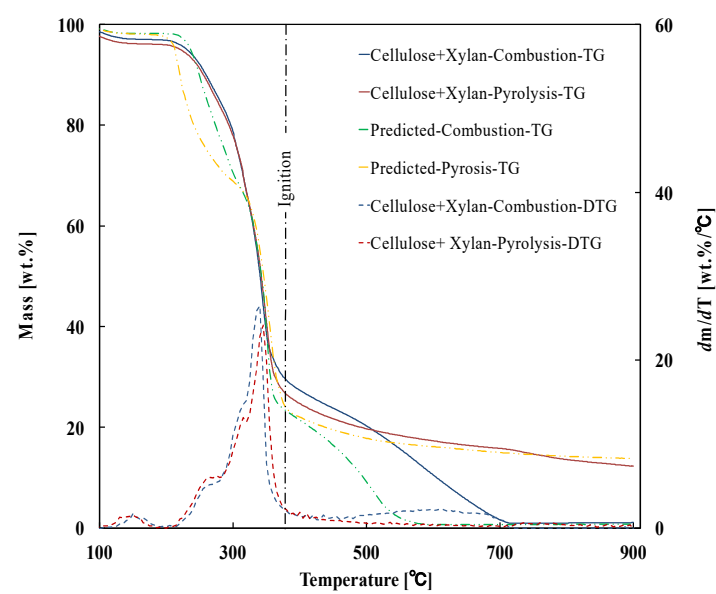

(a) Mixture of Cellulose and Xylan

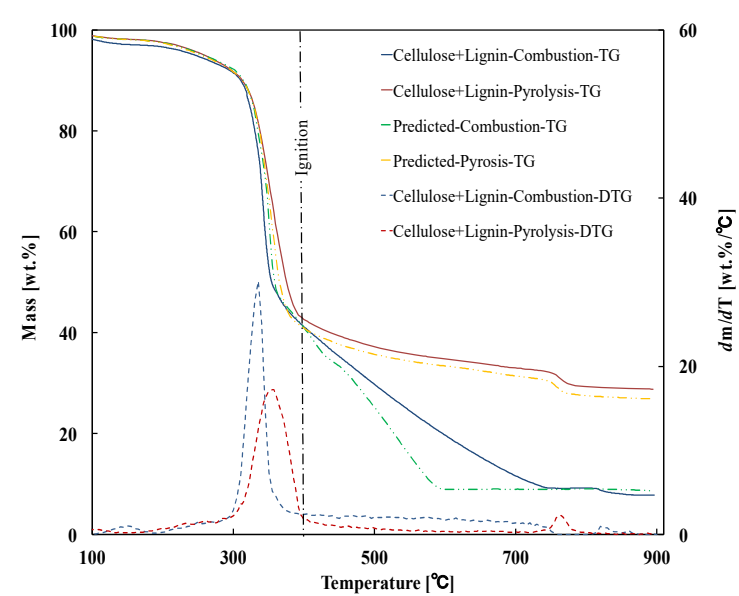

(b) Mixture of Cellulose and Lignin 


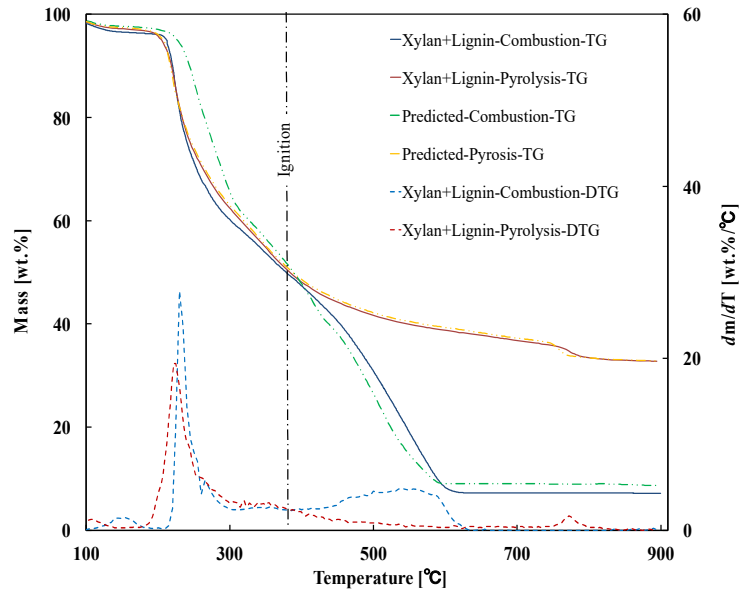

(c) Mixture of Xylan and Lignin

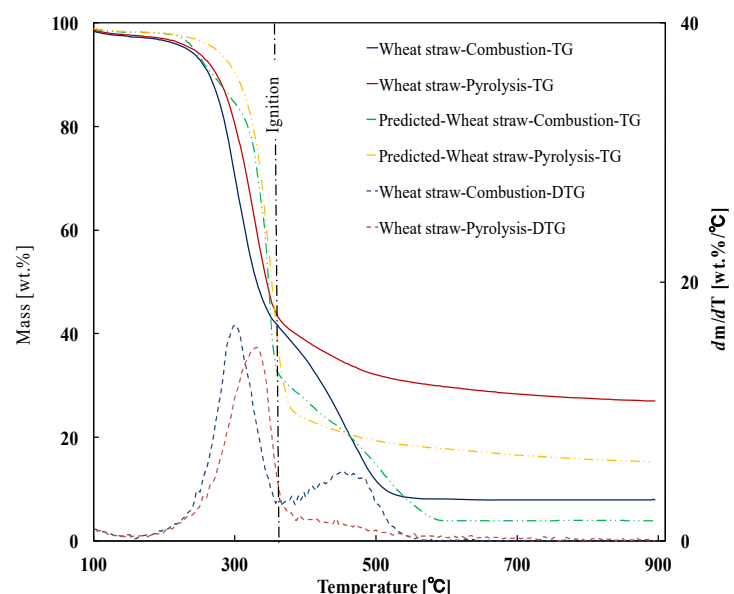

(d) Mixture of Cellulose, Xylan and Lignin (as a prediction of wheat straw)

Fig 2. Thermal characteristics of mixtures of components in air (combustion) and nitrogen (pyrolysis) with identified ignition temperatures along with the prediction results

Fig.2 (a) shows the experimental and predicted results of the mixture of cellulose and xylan, its decomposition starts at a temperature of $250^{\circ} \mathrm{C}$, same as the predicted starting temperature. The significant release of volatile matter of the mixture occurred at the temperature range of $250^{\circ} \mathrm{C}$ to $350^{\circ} \mathrm{C}$, nearly the same as the predicted temperature range. Although there is an obvious burnout delay in the experimental combustion curve compared to that from prediction, where the sample in the experimental curve keeps decomposing till reaching $700^{\circ} \mathrm{C}$, which is a much higher temperature than the ending decomposition temperature of the predicted curve, that is $550^{\circ} \mathrm{C}$, however, this does not affect the identification of ignition temperature. The decomposition of xylan particles at lower temperatures could potentially form a charred film that, acted as a barrier, warps nearby cellulose particles, so that the mass and heat transfer of and between the particles is limited, as stated in Stylianos et al. ${ }^{[15]}$ and Wang et al. ${ }^{[13]}$ studies. There are two detectable diverging temperatures observed in the TG curves of the mixture of cellulose and xylan: one is $370^{\circ} \mathrm{C}$, and the other is $510^{\circ} \mathrm{C}$, leading to a difficult identification of ignition temperature. To address this, the DTG curves are used as complementary information, 
and the ignition temperature of the mixture is defined at $405^{\circ} \mathrm{C}$, compared with the predicted one at $400^{\circ} \mathrm{C}$, indicating that the ignition temperature of the mixture can be predicted from the sum of the individual decomposition data of the mixture component.

Fig.2 (b) shows the decomposition performance of the mixture of cellulose and lignin, which agrees well with the predicted decomposition behaviour. When the temperature reaches to $400^{\circ} \mathrm{C}$, the pyrolysis and combustion curves start to diverge, however, there is an obvious difference in the combustion curve between the experimental and the predicted at the temperature range of $420-730^{\circ} \mathrm{C}$. A prolonged combustion is observed in the experimental curve, this might be caused by the melting and forming of agglomeration of lignin particles, and the agglomerated lignin wrapping nearby cellulose particles ${ }^{[15]}$, lowering the heat transfer efficiency of the particles. In addition, the structure of lignin consists of phenylpropane coupled with $\mathrm{C}-\mathrm{C}$ bond and/or $\mathrm{C}-\mathrm{O}-\mathrm{C}$ bond, which covers an extremely wide decomposition temperature range $\left(152-700^{\circ} \mathrm{C}\right){ }^{[15]}$. Accordingly, above reasons may lead to a higher temperature to burnout, while the ignition characteristics are not affected. The diverging point of the curves in the experiment data occurs at $400^{\circ} \mathrm{C}$ from both TG and DTG results, meaning that the ignition temperature of the mixture is $400^{\circ} \mathrm{C}$, the same as the prediction.

Fig.2 (c) shows the experimental and predicted thermal performance of the mixture of xylan and lignin, which starts to decompose at $210^{\circ} \mathrm{C}$. When temperature exceeds $400^{\circ} \mathrm{C}$, the pyrolysis curve becomes flat, while the combustion curve continues to drop till $600^{\circ} \mathrm{C}$. Both experimental curves coincide with the predicted ones. The diverging point of the curves in the test occurs at $400^{\circ} \mathrm{C}$, which can also be identified in the DTG curves, indicating the ignition temperature of the mixture of xylan and lignin is $400^{\circ} \mathrm{C}$.

At last, a comparison of experimental and predicted performance of wheat straw is presented in Fig.2 (d). The predicted results are similar to that of wheat straw, the decomposition starts 
experimental and predicted results. The combustion curves, however, start the second drop, which is known as char oxidation stage. Since compositions in the wheat straw is more complicate than that in pure component of cellulose, xylan or lignin; this leads to a higher amount of remaining solids from the experiment results when compared with the predicted result, both in pyrolysis and combustion tests. The departing point of the curves in the experiment is at $350^{\circ} \mathrm{C}$, a same result was obtained from the DTG curve; while there are two diverging points observed in predicted curves, the first point agrees well with the experimental result, indicating the ignition temperature of wheat straw could also be acquired by predictions.

As discussed above, the determined ignition temperatures of mixtures (cellulose and lignin, xylan and lignin) are close to the ignition temperature of lignin. Cellulose and xylan have a higher volatile matter content, which means that the major part of them have been released at the pyrolysis stage; lignin, however, has the highest fixed carbon content of all of them, which contributes to the significant amount of char yield after pyrolysis. According to Kai et al. ${ }^{[34]}$, at the combustion stage, the oxidation of the formation of char is characterised by the existence of lignin. This might result in the ignition temperatures of lignin mixtures, being close to the ignition temperature of lignin itself. From the experimental data of all the mixtures, it is observed that the pyrolysis results could be predicted with precision, similar conclusions were also reported by Stylianos et al ${ }^{[15]}$. The synergistic effects between components are less significant but can be observed through the study of combustion curves. There is no significant influence on the ignition behaviour when physically mixing cellulose, xylan and lignin.

\subsection{Thermal characteristics and ignition temperatures of natural and artificial biomass}

To further identify the interaction of chemical components on the ignition properties of biomass, natural and artificial samples (artificial wheat straw (AWS) and artificial soft wood 
280 (ASW)) are tested. The mass fraction of cellulose / hemicellulose / lignin in AWS and ASW that we assumed are 61.3/19.3/19.4 and 43.1/24.1/32.8 respectively. Thermal characteristics of the samples of pyrolysis and combustion are examined by using TGA at the heating rate of $20^{\circ} \mathrm{C} / \mathrm{min}$, the results are presented in Fig. 3 .

The decomposition of wheat straw starts at $250^{\circ} \mathrm{C}$ and softwood starts at $255^{\circ} \mathrm{C}$, and wheat straw lost $60 \%$ of its mass when temperature reaches $350^{\circ} \mathrm{C}$, while softwood lost nearly $70 \%$ of its mass when temperature reaches $405^{\circ} \mathrm{C}$, the mass loss is caused by the release of moisture and volatile content in the mixture, after these temperature points, the pyrolysis and combustion curves start to diverge. When temperature exceeds the diverge points, the pyrolysis curve keeps flattering out till ending, and there is $25 \%$ of its initial mass left as solid residue for wheat straw while it is $20 \%$ for softwood, the residue consists of fixed carbon and ash; however, the combustion curve shows a second mass drop, and wheat straw ends at $520^{\circ} \mathrm{C}$, while softwood finishes at $510^{\circ} \mathrm{C}$, leading to a further mass loss ending with an $18 \%$ and $39 \%$ of its initial mass of wheat straw and softwood respectively, corresponding to the fixed carbon content. In DTG curves, two obvious peaks appear before diverge temperature for both samples, the first one at $100^{\circ} \mathrm{C}$, caused by the evaporation of moisture, and as for the second one, it is $300^{\circ} \mathrm{C}$ for wheat straw and $330^{\circ} \mathrm{C}$ for soft wood, due to the release of the volatile matter. Then pyrolysis curve becomes stable, while combustion curve shows a third peak at $460^{\circ} \mathrm{C}$ for wheat straw, and $500^{\circ} \mathrm{C}$ for soft wood, due to the oxidation of char. In consequence, the ignition temperature of wheat straw and softwood is $350^{\circ} \mathrm{C}$ and $405^{\circ} \mathrm{C}$ respectively, which can also be observed from the DTG curve in Fig. 3 (a) and (b), similar ignition temperatures can also be obtained from the studies of $[3,35]$, 


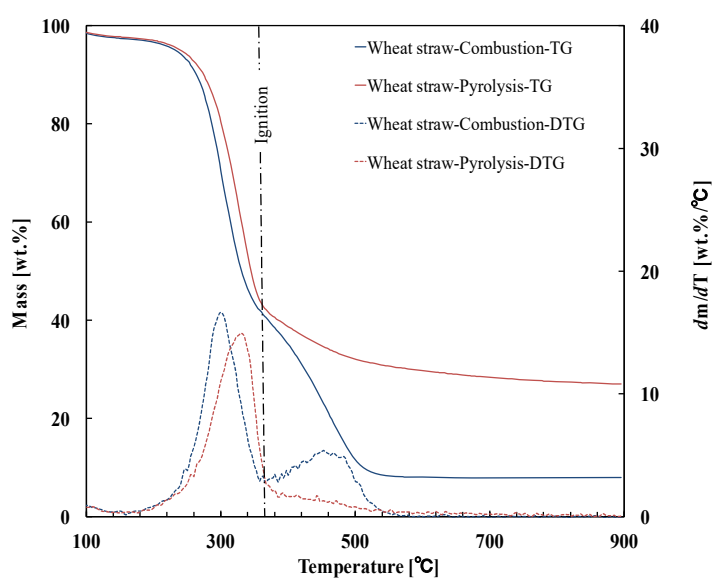

(a) Wheat straw

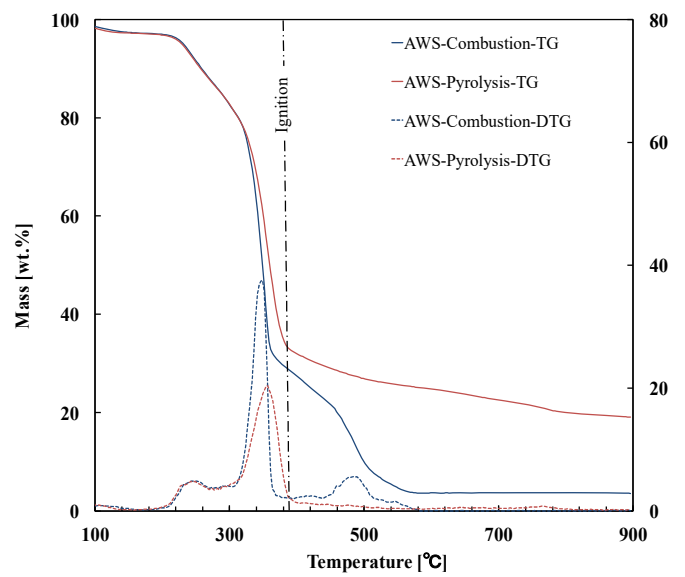

(c) Artificial wheat straw (AWS)

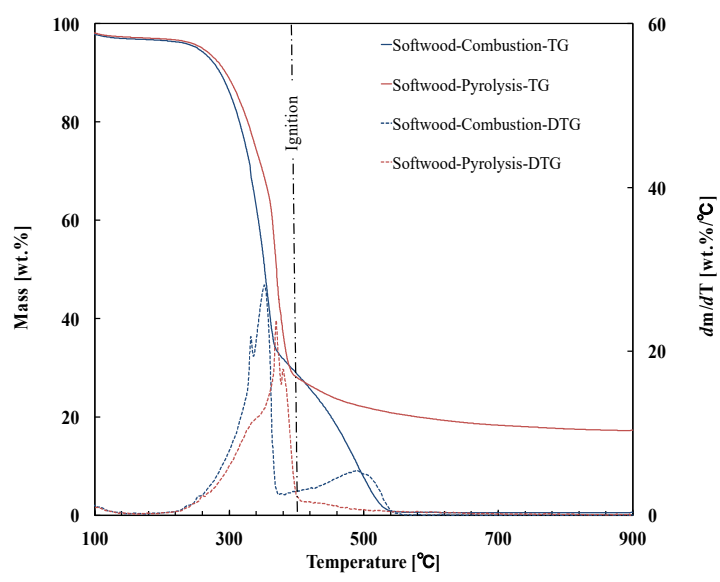

(b) Softwood

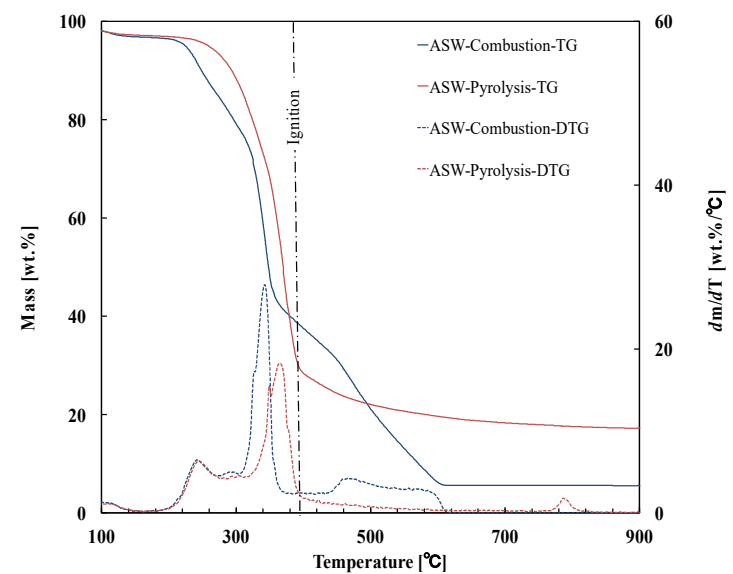

(d) Artificial softwood (ASW)

Fig.3. Thermal characteristics of biomass samples in air and nitrogen with identified ignition temperature:

(a) wheat straw; (b) soft wood; (c) artificial wheat straw (AWS); (d) artificial softwood (ASW)

Fig. 3 (c) and (d) show the thermal decomposition results for artificial biomass with the similar

trends as that of natural biomass. The first phase decomposition of artificial wheat straw (AWS) starts at $220^{\circ} \mathrm{C}$ and ends at $365^{\circ} \mathrm{C}$, two steep decreasing of mass occurred during this phase, both in pyrolysis and combustion curves. The first decrease starts from $220^{\circ} \mathrm{C}$ to $340^{\circ} \mathrm{C}$ in $\mathrm{TG}$ curves, reaching its peak at $260^{\circ} \mathrm{C}$ in DTG curves, this is mainly caused by the decomposition of xylan, the least thermally stable component in biomass ${ }^{[36]}$, due to the breakdown of its C- 
starts to decompose at $180^{\circ} \mathrm{C}$ and sharply loses $65 \%$ of its mass before $300^{\circ} \mathrm{C}$, while partial cellulose and lignin start to decompose at lower temperatures, this implies that the existence of cellulose and lignin doesn't affect the thermal behaviour of xylan significantly. The second decrease starts from $340^{\circ} \mathrm{C}$ to $380^{\circ} \mathrm{C}$ in the TG curves, and as can be seen in the DTG curve, it reaches its peak at $355^{\circ} \mathrm{C}$. As illustrated in Fig. 1, during this temperature range, cellulose loses nearly $90 \%$ of its initial mass, lignin loses $15 \%$, and xylan loses only $4 \%$, indicating that cellulose and lignin are the main components that attribute the mass loss during this stage. The pyrolysis and combustion curves of AWS start to diverge at $375^{\circ} \mathrm{C}$. After that, in the pyrolysis scenario, AWS continues to lose mass very slowly with a remaining of $20 \%$ of its initial mass at the end of the test, which is the same as the sum of partial contributions of fixed carbon and ash contents of each component. While for the combustion scenario, most of the mass loss at the char oxidation stage is attributed to lignin and xylan, since both of them have higher fixed carbon contents (33.7 wt.\% in lignin; $13.5 \mathrm{wt} \%$ in xylan) compared to cellulose (8.6 wt.\%). As shown in both TG and DTG curves, the ignition temperature of the AWS is $375^{\circ} \mathrm{C}$. As for artificial softwood (ASW), similar conclusion can be summarised as AWS, the decomposition of each component is distinguishable. The first phase decomposition begins at $210^{\circ} \mathrm{C}$, till to $360^{\circ} \mathrm{C}$ for combustion and it is $240^{\circ} \mathrm{C}-390^{\circ} \mathrm{C}$ for pyrolysis, two drops of mass occurred during this phase. The first drop starts from $210^{\circ} \mathrm{C}$ to $330^{\circ} \mathrm{C}$ in combustion curve, while it is $240^{\circ} \mathrm{C}-350^{\circ} \mathrm{C}$ for pyrolysis curve. As showed in Table 2, the content of xylan in ASW is similar to that of AWS, which leading to the semblable temperature range of first drop. The second drop of mass happened from $330^{\circ} \mathrm{C}$ to $360^{\circ} \mathrm{C}$ in combustion curve and from $350^{\circ} \mathrm{C}$ to $390^{\circ} \mathrm{C}$ in pyrolysis curve, due to the decomposition of cellulose and lignin. After $390^{\circ} \mathrm{C}$, the pyrolysis curve becomes flat and with $20 \%$ remaining at the end; while the combustion curve happened the char oxidation phase, and the remaining equals to the sum of partial contributions of ash contents of each component. There are two notable diverging points in Fig 3 (d), one is 
$385^{\circ} \mathrm{C}$, and the other one is $495^{\circ} \mathrm{C}$, by complementing the DTG information, the ignition temperature of ASW is defined at $395^{\circ} \mathrm{C}$, similar to that of natural softwood. It can be seen that the ignition temperature of ASW is close to that of lignin, since the fraction of lignin in ASW is much higher than that in AWS, indicating that the lignin is the dominant factor that influence the ignition temperature of the samples.

As discussed above, thermal behaviour of AWS and ASW could be predicted through the sum of the decomposition behaviour of individual components. As aforementioned, the ignition temperature and thermal behaviour of the artificial biomass is similar to that of natural biomass, meaning that the ignition temperatures of various biomass materials are predictable once the mass fractions of these individual components are certain. Nevertheless, there is a slight difference between the ignition temperature of natural and artificial biomass can be observed, reveals the potential interactions among the three chemical components in natural biomass, which might affect its ignition behaviour; also, the moisture content of the artificial biomass is different from that of natural biomass, and the variation of moisture content in the samples may have an influence on the ignition characteristics ${ }^{[38]}$, a summary of the comparison of moisture content and ignition temperature is list below in Table 3. It can be seen that the higher the moisture content, the higher the ignition temperature. The increased moisture content will increase the thermal properties of materials, like: thermal conductivity and specific heat, as well as the vaporization and migration of moisture ${ }^{[39]}$, leading to the delay of ignition as a function of external heat flux and substantially alters the thermos-physical properties of the biomass samples ${ }^{[40]}$.

It also should be noticed that the structures of cellulose, xylan and lignin in biomass differ from the commercial materials, as well as in the different biomass fuels, and the different structures would result in varying ignition properties. Besides, the structure of biomass is complicated, the chemical component cellulose provides the skeletal structure of the biomass that is coated 
with hemicellulose and cemented by lignin ${ }^{[20,41]}$, co-existence with the ash and moisture; the artificial biomass is made by physical mixing of these three components that is unable to mimic the inner tangles of them precisely. Above results can provide a general perspective of the ignition behaviour of three chemical components and their mixtures, and to predict the ignition temperature of natural biomass.

Table 3. The summary of moisture content and ignition temperature of natural and artificial biomass.

\begin{tabular}{lcccc}
\hline & Wheat straw & Artificial wheat straw & Softwood & Artificial softwood \\
& & & & \\
\hline Moisture content (wt. \%) & 2.30 & $2.84^{*}$ & 3.50 & $2.91^{*}$ \\
\hline Ignition temperature $\left({ }^{\circ} \mathrm{C}\right)$ & 350 & 375 & 405 & 395
\end{tabular}

*The moisture content of artificial biomass is the sum of partial contributions of moisture content of each component.

\subsection{Kinetic study on the interactions}

Former study on the ignition behaviour of samples has indicated the possibilities to estimate the ignition temperature of biomass when the fractions of three chemical components are certain, but the variation of the ignition temperatures between artificial and natural biomass illustrates the potential interactions among the chemical components may influence the ignition behaviour. In order to further understand the mutual interactions, and how they affect the combustion process, Coats-Redfern method was used to calculate the kinetic parameters of the combustion of all the samples, and the changes of activation energy $\left(E_{a}\right)$ and pre-exponential factor $(A)$ will be discussed to investigate the interactions among the cellulose, xylan and lignin. As discussed in Sec. 2.4, the process of combustion in this study is divided into two steps: pyrolysis and char oxidation. The combustion kinetic parameters of the studied individual components and the one from the mixture samples obtained from the calculations are shown in Table 4, together with the summarised ignition temperatures. At the stage of pyrolysis, the values of $E_{a}$ for cellulose, xylan and lignin are $223.32 \mathrm{~kJ} / \mathrm{mol}, 73.85 \mathrm{~kJ} / \mathrm{mol}$ and $23.41 \mathrm{~kJ} / \mathrm{mol}$ 
respectively. Cellulose has the highest $E_{a}$ value among them, followed by xylan, similar results are also reported by Milosavljevic et al. ${ }^{[42]}$. This result indicates that the decomposition of cellulose is a crucial step to determine the overall rate of the biomass combustion process ${ }^{[17]}$, while xylan and lignin dominate the initial decomposition.

The obtained correlation coefficients $\left(\boldsymbol{R}^{2}\right)$ of cellulose and xylan at their second step are not high enough to be trusted, indicating a completion of decomposition of cellulose and xylan at the early stage of pyrolysis, so that the first order reaction model might not be suitable for the combustion of cellulose and xylan ${ }^{[43]}$. While the correlation coefficient at the step 2 of combustion of lignin is reliable, indicating the feasibility of first order reaction model on both steps of combustion of lignin. The $E_{a}$ value for lignin in step 2 is $45.98 \mathrm{~kJ} / \mathrm{mol}$, higher than that of step 1 , this is attributed to the high energy required to decompose inorganic matter ${ }^{[44]}$, since lignin has the highest ash content among these three components.

For the mixture of cellulose and xylan, the $E_{a}$ value in step 1 is $54.64 \mathrm{~kJ} / \mathrm{mol}$ which is lower than that of either cellulose or xylan, suggests the potential interactions between them could affect the reaction process during the pyrolysis. At devolatilization stage, xylan begins to decompose prior to cellulose and forming char residues that might cover and wrap around the cellulose surface, which inhibits the release of volatile products and enhances the secondary degradation of macromolecular materials in cellulose. For the mixture of cellulose and lignin, $E_{a}$ value is $152.74 \mathrm{~kJ} / \mathrm{mol}$ in step 1, which is placed in between of that of cellulose and xylan. The existence of lignin in the mixture enhances the cellulose to generate small molecular products during the devolatilization process ${ }^{[45]}$, so that the mixture requires lower energy to devolatilize compared to cellulose. And the $E_{a}$ value for the mixture of lignin and xylan is $62.01 \mathrm{~kJ} / \mathrm{mol}$ in step 1 , which is in the range of the activation energy of lignin and xylan. However, for all the three mixtures, correlation coefficients are all rather small in their second step, indicating the first order reaction model is not suitable for describing the combustion of 
Table 4. Kinetic parameters of combustion of individual component.

\begin{tabular}{|c|c|c|c|c|c|}
\hline & $\begin{array}{c}\text { Ignition } \\
\text { temp. }\left({ }^{\circ} \mathrm{C}\right)\end{array}$ & $\begin{array}{c}\text { Temp. } \\
\text { range }\left({ }^{\circ} \mathrm{C}\right)\end{array}$ & $\begin{array}{c}\boldsymbol{E}_{\boldsymbol{a}} \\
(\mathrm{kJ} / \mathrm{mol})\end{array}$ & $\begin{array}{c}A \\
(1 / \mathrm{s})\end{array}$ & $\overline{R^{2}}$ \\
\hline \multirow[t]{2}{*}{ Cellulose } & 410 & $314-362^{1}$ & 223.32 & $5.87 \mathrm{E}+18$ & 0.9967 \\
\hline & & $382-584(2)$ & - & - & - \\
\hline \multirow[t]{2}{*}{ Xylan } & 350 & $230-308^{1}$ & 73.85 & $2.76 \mathrm{E}+06$ & 0.9385 \\
\hline & & $310-550^{2}$ & - & - & - \\
\hline \multirow[t]{2}{*}{ Lignin } & 405 & $223-453^{1}$ & 23.41 & $4.03 \mathrm{E}+00$ & 0.9934 \\
\hline & & $456-591^{2}$ & 45.98 & $2.88 \mathrm{E}+02$ & 0.9329 \\
\hline \multirow[t]{2}{*}{ Cellulose \& Xylan } & 405 & $245-355^{1}$ & 54.64 & $1.01 \mathrm{E}+04$ & 0.9824 \\
\hline & & $400-700^{2}$ & - & - & - \\
\hline \multirow[t]{2}{*}{ Cellulose \& Lignin } & 400 & $320-3501$ & 152.74 & $4.27 \mathrm{E}+12$ & 0.9892 \\
\hline & & $360-710^{2}$ & - & - & - \\
\hline \multirow[t]{2}{*}{ Lignin \& Xylan } & 400 & $212-269$ (1) & 62.01 & $2.89 \mathrm{E}+05$ & 0.8437 \\
\hline & & $277-595^{2}$ & - & - & - \\
\hline \multirow[t]{2}{*}{ Wheat straw } & 350 & $247-3521$ & 62.58 & $2.69 \mathrm{E}+05$ & 0.9814 \\
\hline & & $352-502(2)$ & 20.31 & $5.19 \mathrm{E}+00$ & 0.9746 \\
\hline \multirow[t]{2}{*}{ AWS } & 375 & $248-358^{1}$ & 44.93 & $9.41 \mathrm{E}+02$ & 0.8753 \\
\hline & & $361-551^{2}$ & 17.43 & $2.86 \mathrm{E}+00$ & 0.7952 \\
\hline \multirow[t]{2}{*}{ Soft wood } & 405 & $260-380^{1}$ & 70.46 & $2.22 \mathrm{E}+05$ & 0.9889 \\
\hline & & $390-510^{2}$ & 23.83 & $9.76 \mathrm{E}+00$ & 0.9016 \\
\hline \multirow[t]{2}{*}{ ASW } & 395 & $227-363^{1}$ & 40.67 & $4.25 \mathrm{E}+02$ & 0.9557 \\
\hline & & $377-570^{2}$ & 13.45 & $8.14 \mathrm{E}-01$ & 0.8891 \\
\hline
\end{tabular}

Note: ${ }^{1}$ step 1 (pyrolysis) of the combustion process; ${ }^{2}$ step 2 (char oxidation) of the combustion process

413 The obtained kinetic parameters of the natural and artificial biomass are also listed in Table 4.

414 In step 1, the value of $E_{a}$ for the natural biomass are all higher than that of the artificial biomass,

415 with $62.85 \mathrm{~kJ} / \mathrm{mol}$ and $70.46 \mathrm{~kJ} / \mathrm{mol}$ for wheat straw and softwood respectively, compared to $41644.93 \mathrm{~kJ} / \mathrm{mol}$ and $40.67 \mathrm{~kJ} / \mathrm{mol}$ for artificial wheat straw and artificial softwood respectively.

417 Same trends are also observed by the results of step 2, the value of $E_{a}$ for the natural biomass 418 are within $20-25 \mathrm{~kJ} / \mathrm{mol}$, while it is $13-18 \mathrm{~kJ} / \mathrm{mol}$ for the artificial biomass. It can be seen, the 419 activation energy obtained in step 2 are all smaller than that in step 1, meaning that the char 420 oxidation requires less energy to react than the release of volatile matter. Meanwhile, the values 
of $E_{a}$ for artificial biomass are all smaller than that of natural biomass in both two steps. In fact, there exist interactions among cellulose, hemicellulose and lignin in natural biomass, such as the existence of hydrogen bonding between cellulose and lignin ${ }^{[46]}$, as well as cellulose and hemicellulose, and also the presence of covalent linkages between cellulose and lignin ${ }^{[47]}$, these bonds require more energy to break up, leading to the higher value of $E_{a}$ for natural biomass than that of artificial biomass. Besides, the chemical and physical interactions within cellulose-hemicellulose-lignin in actual biomass could generate different local reaction conditions ${ }^{[46]}$ which cannot be mimicked in a simple physical mixture of the individual components. All these could result in the difference of kinetic results between natural and artificial biomass.

For the tests of mixtures and biomass, the calculated $E_{a}$ are within the approximate range from 1 to $180 \mathrm{~kJ} / \mathrm{mol}{ }^{[48]}$. The obtained kinetic parameters reflect the fact that even when the components are physically mixed, the interactions among them affects the reaction process.

\section{Conclusion}

In this paper, thermal behaviour of cellulose, xylan, lignin, their mixtures and natural biomass have been studied by using TGA. For all the tested samples, temperature is the dominant factor that influences their thermal behaviour at the pyrolysis stage, regardless of the presence of oxygen. Ignition temperatures of cellulose, xylan and lignin were determined by using TG and DTG curves as $410^{\circ} \mathrm{C}, 370^{\circ} \mathrm{C}$ and $405^{\circ} \mathrm{C}$ respectively. Thermal behaviour of the mixtures could be predicted according to that of individual components, and the ignition temperature is dominated by lignin when lignin exists in the mixtures, while cellulose dominates the ignition temperature of the mixture of cellulose and xylan. The ignition temperature of natural wheat straw is $350^{\circ} \mathrm{C}$ when compared with $365^{\circ} \mathrm{C}$ of artificial wheat straw, and it is $405^{\circ} \mathrm{C}$ for natural softwood and $395^{\circ} \mathrm{C}$ for artificial softwood respectively, the influence of mutual interactions 
among the components on the ignition behaviour is insignificant, and the results demonstrated a similar thermal behaviour between native and artificial biomass. The reaction kinetics of the samples are studied by using Coats-Redfern method, and the results indicate that first order kinetic model was fitted to most of the samples in the tests, especially natural biomass. The study of the changing of activation energy values from the individuals to the mixtures revealed the influence of mutual interactions among the components is significant on the thermal conversion process during the combustion. Future efforts should focus on testing the different kinds of chemical components, monitoring the products yields/evolution and the structure changes of mixtures.

\section{Acknowledgements}

Authors would like to thank the Scottish Funding Council-Global Challenge Research Fund and the EU-Biofuels Research Infrastructure for Sharing Knowledge (BRISK) for their financial support of this work.

\section{References}

1. Zhao, H.-b., et al., Study on the Transformation of Inherent Potassium during the Fast-Pyrolysis Process of Rice Straw. Energy \& Fuels, 2015. 29(10): p. 6404-6411.

2. Nussbaumer, T., Combustion and co-combustion of biomass: fundamentals, technologies, and primary measures for emission reduction. Energy \& fuels, 2003. 17(6): p. 1510-1521.

3. Li, J., M.C. Paul, and K.M. Czajka, Studies of Ignition Behavior of Biomass Particles in a Down-Fire Reactor for Improving Co-firing Performance. Energy \& Fuels, 2016. 30(7): p. 5870-5877.

4. Grotkjær, T., et al., An experimental study of biomass ignition $九$. Fuel, 2003. 82(7): p. 825-833.

5. Yang, H., et al., Coal ignition characteristics in CFB boiler. Fuel, 2005. 84(14): p. 1849-1853.

6. Jones, J., et al., Low temperature ignition of biomass. Fuel Processing Technology, 2015. 134: p. 372-377.

7. Riaza, J., et al., Ignition behavior of coal and biomass blends under oxy-firing conditions with steam additions. Greenhouse Gases: Science and Technology, 2013. 3(5): p. 397-414.

8. Shan, F., et al., An experimental study of ignition and combustion of single biomass pellets in air and oxyfuel. Fuel, 2017. 188: p. 277-284. 
9. Zhang, L., C.C. Xu, and P. Champagne, Overview of recent advances in thermo-chemical conversion of biomass. Energy Conversion and Management, 2010. 51(5): p. 969-982.

10. Raveendran, K., A. Ganesh, and K.C. Khilar, Pyrolysis characteristics of biomass and biomass components. Fuel, 1996. 75(8): p. 987-998.

11. Worasuwannarak, N., T. Sonobe, and W. Tanthapanichakoon, Pyrolysis behaviors of rice straw, rice husk, and corncob by TG-MS technique. Journal of Analytical and Applied Pyrolysis, 2007. 78(2): p. 265-271.

12. Wang, G., et al., TG study on pyrolysis of biomass and its three components under syngas. Fuel, 2008. 87(4): p. 552-558.

13. Wang, S., et al., Influence of the interaction of components on the pyrolysis behavior of biomass. Journal of Analytical and Applied Pyrolysis, 2011.91(1): p. 183-189.

14. Yang, H., et al., In-depth investigation of biomass pyrolysis based on three major components: hemicellulose, cellulose and lignin. Energy \& Fuels, 2006. 20(1): p. 388-393.

15. Stefanidis, S.D., et al., A study of lignocellulosic biomass pyrolysis via the pyrolysis of cellulose, hemicellulose and lignin. Journal of Analytical and Applied Pyrolysis, 2014. 105: p. 143-150.

16. Galwey, A.K. and M.E. Brown, Kinetic background to thermal analysis and calorimetry, in Handbook of thermal analysis and calorimetry. 1998, Elsevier. p. 147-224.

17. White, J.E., W.J. Catallo, and B.L. Legendre, Biomass pyrolysis kinetics: a comparative critical review with relevant agricultural residue case studies. Journal of Analytical and Applied Pyrolysis, 2011. 91(1): p. 1-33.

18. Mohan, D., C.U. Pittman, and P.H. Steele, Pyrolysis of wood/biomass for bio-oil: a critical review. Energy \& fuels, 2006. 20(3): p. 848-889.

19. Diebold, J. and A. Bridgwater, Overview of fast pyrolysis of biomass for the production of liquid fuels, in Developments in thermochemical biomass conversion. 1997, Springer. p. 5-23.

20. Klass, D.L., Biomass for renewable energy, fuels, and chemicals. 1998: Academic press.

21. Di Blasi, C., et al., Product distribution from pyrolysis of wood and agricultural residues. Industrial \& Engineering Chemistry Research, 1999. 38(6): p. 2216-2224.

22. Campos-M, M. and R. Campos-C, Applications of quartering method in soils and foods. Vol. 7. 2017. 35-39.

23. Tetteh, J., E. Metcalfe, and S.L. Howells, Optimisation of radial basis and backpropagation neural networks for modelling auto-ignition temperature by quantitative-structure property relationships. Chemometrics and intelligent laboratory systems, 1996. 32(2): p. 177-191.

24. Wang, C.a., et al., Pyrolysis and combustion characteristics of coals in oxyfuel combustion. Applied Energy, 2012. 97: p. 264-273.

25. Arenillas, A., et al., A TG/DTA study on the effect of coal blending on ignition behaviour. Journal of Thermal Analysis and Calorimetry, 2004. 76(2): p. 603-614.

26. Wang, C., et al., Thermogravimetric studies of the behavior of wheat straw with added coal during combustion. Biomass and Bioenergy, 2009. 33(1): p. 50-56. 
27. Fan, Y.-s., et al., Ignition characteristics of pulverized coal under high oxygen concentrations. Energy \& Fuels, 2008. 22(2): p. 892-897.

28. Chen, Y., S. Mori, and W.-P. Pan, Studying the mechanisms of ignition of coal particles by TG-DTA. Thermochimica Acta, 1996. 275(1): p. 149-158.

29. Fang, X., L. Jia, and L. Yin, A weighted average global process model based on two- stage kinetic scheme for biomass combustion. Biomass and Bioenergy, 2013. 48: p. 43-50.

30. Wang, G., et al., Characterisation and model fitting kinetic analysis of coal/biomass co-combustion. Thermochimica Acta, 2014. 591: p. 68-74.

31. Gil, M.V., et al., Thermal behaviour and kinetics of coal/biomass blends during co-combustion. Bioresource Technology, 2010. 101(14): p. 5601-5608.

32. Shen, D., et al., Kinetic study on thermal decomposition of woods in oxidative environment. Fuel, 2009. 88(6): p. 1024-1030.

33. Shi, H., Kinetic study of fire combustible pyrolysis. Zhejiang University, Hangzhou, 2004: p. $20-21$.

34. Kai, X., et al. The effect of biomass components on the co-combustion characteristics of biomass with coal. in Digital Manufacturing and Automation (ICDMA), 2011 Second International Conference on. 2011. IEEE.

35. Li, Y. and D. Drysdale, Measurement of the ignition temperature of wood. Fire Safety Science, 1992. 1: p. 380-385.

36. López-González, D., et al., Thermogravimetric-mass spectrometric analysis on combustion of lignocellulosic biomass. Bioresource technology, 2013. 143: p. 562-574.

37. Cheng, K., W.T. Winter, and A.J. Stipanovic, A modulated-TGA approach to the kinetics of lignocellulosic biomass pyrolysis/combustion. Polymer Degradation and Stability, 2012. 97(9): p. 1606-1615.

38. Khan, M.M., J.L. De Ris, and S.D. Ogden, Effect of moisture on ignition time of cellulosic materials. Fire Safety Science, 2008. 9: p. 167-178.

39. Atreya, A. and M. Abu-Zaid, Effect of environmental variables on piloted ignition. Fire Safety Science, 1991. 3: p. 177-186.

40. Moghtaderi, B., et al., A new correlation for bench-scale piloted ignition data of wood. Fire safety journal, 1997. 29(1): p. 41-59.

41. Sorek, N., et al., The implications of lignocellulosic biomass chemical composition for the production of advanced biofuels. BioScience, 2014. 64(3): p. 192-201.

42. Milosavljevic, I. and E.M. Suuberg, Cellulose thermal decomposition kinetics: global mass loss kinetics. Industrial \& Engineering Chemistry Research, 1995. 34(4): p. 1081-1091.

43. Álvarez, A., et al., Determination of kinetic parameters for biomass combustion. Bioresource technology, 2016. 216: p. 36-43.

44. Wang, S., et al., Combustion characteristics of seaweed biomass. 1. Combustion characteristics of Enteromorpha clathrata and Sargassum natans. Energy \& Fuels, 2009. 23(10): p. 5173-5178. 
45. Hosoya, T., H. Kawamoto, and S. Saka, Cellulose-hemicellulose and cellulose-lignin interactions in wood pyrolysis at gasification temperature. Journal of analytical and applied pyrolysis, 2007. 80(1): p. 118-125.

544 46.Zhang, J., et al., Cellulose-hemicellulose and cellulose-lignin interactions during fast pyrolysis. ACS Sustainable Chemistry \& Engineering, 2015. 3(2): p. 293-301.

546 47. Jin, Z., et al., Covalent linkages between cellulose and lignin in cell walls of coniferous and nonconiferous woods. Biopolymers, 2006. 83(2): p. 103-110.

548 48. Garcia-Maraver, A., et al., Determination and comparison of combustion kinetics parameters of agricultural biomass from olive trees. Renewable Energy, 2015. 83: p. 897-904. 